\title{
Immunization with antigenic peptides complexed with $\beta$-glucan induces potent cytotoxic $T$-lymphocyte activity in combination with CpG-ODNs
}

Shinichi Mochizuki ${ }^{\text {a, }}$, Hiromi Morishita ${ }^{a}$, Kouji Kobiyama ${ }^{\text {bcc }}$, Taiki Aoshi ${ }^{\text {b,c,d }}$, Ken J. Ishii ${ }^{\text {b,c }}$, Kazuo Sakurai, ${ }^{\text {a, }}$

${ }^{a}$ Department of Chemistry and Biochemistry, The University of Kitakyushu, 1-1, Hibikino, Wakamatsu-ku, Kitakyushu, Fukuoka, 808-0135, Japan.

${ }^{\mathrm{b}}$ Laboratory of Adjuvant Innovation, National Institute of Biomedical Innovation, 7-6-8, Asagi Saito, Ibaraki, Osaka, 567-0085, Japan.

${ }^{\mathrm{c}}$ Laboratory of Vaccine Science, Immunology Frontier Research Center (iFReC), Osaka University, 1-1, Yamadaoka, Suita, Osaka 565-0871, Japan

${ }^{\mathrm{d}}$ Vaccine Dynamics Project, BIKEN Innovative Vaccine Research Alliance Laboratories, Research Institute for Microbial Diseases (RIMD), Osaka University, 1-1, Yamadaoka, Suita, Osaka 565-0871, Japan

*Corresponding author. Department of Chemistry and Biochemistry, The University of Kitakyushu, 1-1, Hibikino, Wakamatsu-ku, Kitakyushu, Fukuoka, 808-0135, Japan.

Tel: +81-93-695-3298; Fax: +81-93-695-3390

E-mail address: mochizuki@kitakyu-u.ac.jp, sakurai@kitakyu-u.ac.jp

\begin{abstract}
The induction of antigen-specific immune responses requires immunization with not only antigens, but also adjuvants. $\mathrm{CpG}$ oligonucleotides (CpG-ODNs) are well-known ligands for Toll-like receptor 9 and a potent adjuvant that induces both Th1-type humoral and cellular immune responses including cytotoxic T-lymphocyte responses. We previously demonstrated that $\beta$-glucan schizophyllan (SPG) can form complexes with $\mathrm{CpG}-\mathrm{ODNs}$ with attached $\mathrm{dA}_{40}(\mathrm{CpG}-\mathrm{dA} / \mathrm{SPG})$, which can accumulate in macrophages in the draining inguinal lymph nodes and induce strong immune responses by co-administration of antigenic proteins, namely ovalbumin (OVA). Immunization with antigenic peptides, $\mathrm{OVA}_{257-264}$, did not induce these antigen-specific immune responses even in combination with $\mathrm{CpG}-\mathrm{dA} / \mathrm{SPG}$, indicating peptides require a carrier to antigen presenting cells. In this study, we prepared conjugates comprising $\mathrm{OVA}_{257-264}$ and $\mathrm{dA}_{40}$, and made complexes with SPG. Immunization with

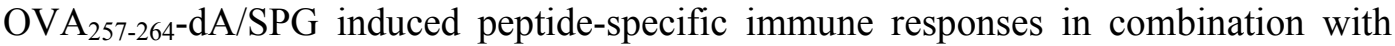
CpG-dA regardless of complexation with SPG both in vitro and in vivo. When splenocytes from immunized mice were incubated with E.G7-OVA tumor model cells presenting OVA peptides, the number of cells drastically decreased after 24 hours.

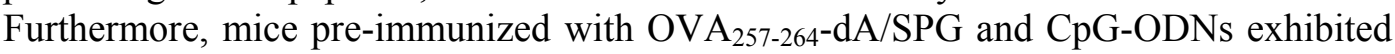
a long delay in tumor growth after tumor inoculation. Therefore, these peptide-dA/SPG and $\mathrm{CpG}-\mathrm{dA} / \mathrm{SPG}$ complexes could be used as a potent vaccine for the treatment of cancers and infectious diseases.
\end{abstract}

Key words

Cancer vaccine, peptide vaccine, $\mathrm{CpG}-\mathrm{ODN}$, antigen presenting cell, $\beta$-glucan 


\section{Introduction}

The treatment of tumors by immunotherapy requires the induction of tumor-specific cytotoxic T-lymphocytes (CTLs), which recognize and eradicate tumor cells $[1,2]$. Although pre-clinical and clinical trials of tumor treatments mostly using antigenic peptide-based vaccines have been performed since the mid-1990s [3, 4], few vaccines exhibit sufficient therapeutic efficacy for cancer patients. A promising strategy for overcoming this problem and inducing high CTL responses in vivo is to facilitate the uptakes of not only the tumor-associated antigens, but also adjuvant molecules specifically into antigen presenting cells (APCs) such as dendritic cells and macrophages [5]. APCs play a central role in the induction of CTL responses [6-8]. They present peptide epitopes derived from tumor proteins on the cellular surface via major histocompatibility complex (MHC)-I molecules. These presented epitopes are subsequently recognized by antigen specific $\mathrm{T}$ cells, leading to their activation.

Adjuvants enhance antigen-specific (i.e., adaptive) immune responses when used in combination with an antigen. $\mathrm{CpG}$ oligonucleotides (CpG-ODNs) containing the immunostimulatory $\mathrm{CpG}$ motif can activate APCs by binding to Toll-like receptor 9 (TLR9) localized in endosomal compartments [9, 10]. After activation, APCs produce type I interferons and inflammatory cytokines, inducing Th1-type humoral and cellular immune responses including CTL responses [11, 12]. One reason for the low therapeutic efficacy of treatments with antigens and adjuvants for cancer patients is nonspecific uptake by cells other than APCs. Therefore, the development of an efficient antigen and/or adjuvant delivery system for APCs is a primary requirement for clinical applications of cancer vaccine therapies.

Schizophyllan (SPG) is a $\beta$-glucan that comprises a main $(1 \rightarrow 3)-\beta$-D-glucan chain and a $(1 \rightarrow 6)-\beta$-D-glycosyl side chain that links to the main chain at every three glucose residues. SPG forms a stoichiometric complex with specific homo nucleotides such as $\operatorname{poly}(\mathrm{C})$ or poly $(\mathrm{dA})$ via interactions between its two main chain glucoses with one nucleotide base $[13,14]$. We previously studied SPG as a delivery carrier of therapeutic oligonucleotides such as antisense ODN or short interfering RNA with attached dA 40mer $\left(\mathrm{dA}_{40}\right)$ and achieved efficient gene silencing in animal models of fulminant hepatitis and bowel disease [15-17].

When CpG-dA 40 was complexed with SPG (CpG-dA/SPG; Figure 1) and administered with antigenic proteins at the tail base in mice, strong antigen-specific humoral and cellular immune responses were induced [18]. These powerful adjuvant activities are attributed to $\mathrm{CpG}-\mathrm{dA} / \mathrm{SPG}$ uptake into macrophages and dendritic cells in drain lymph nodes. As $\beta$-1,3-glucans exist on fungal cell walls and are recognized by the innate immune system [19], the CpG-dA/SPG could also be easily recognized by such immune cells. Many studies demonstrate that antigenic proteins must conjugate with or be encapsulated in carriers or particles to induce immune responses [20-22]. However, we were able to induce antigen-specific immune responses without any conjugation or encapsulation of antigenic proteins. Furthermore, immunization with a mixture of CpG-dA/SPG and influenza split vaccine protected mice against a heterologous challenge of lethal virus, suggesting CpG-dA/SPG can be used as a potent adjuvant for protein vaccines such as influenza split vaccines. 
Figure 1

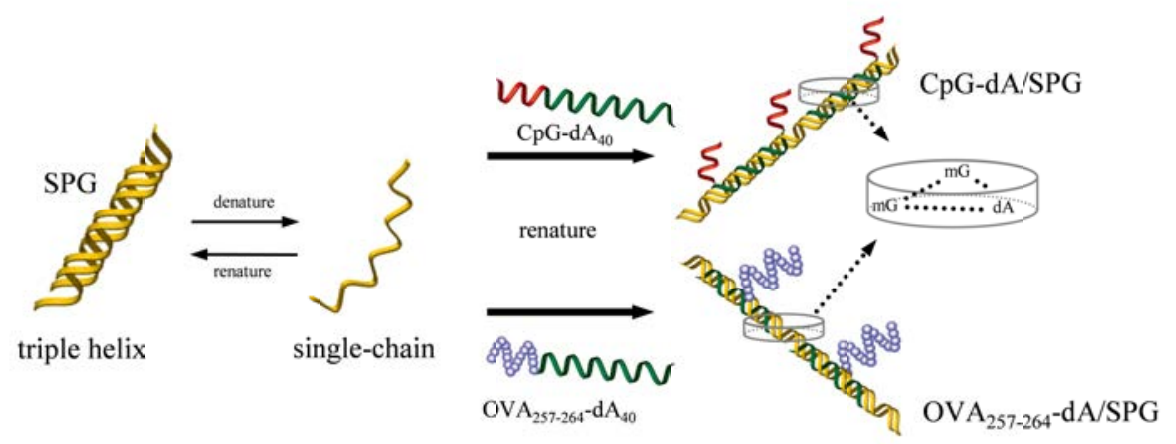

Our previous study principally used antigens in the form of protein or its split. However, considering the presented antigens on MHC class I and II molecules, MHC molecule-restricted peptides are sufficient as an antigen instead of proteins [23]. Therefore, the present study evaluated the immune responses and CTL activities of tumor model cells by immunization with $\mathrm{CpG}-\mathrm{dA} / \mathrm{SPG}$ and antigenic proteins or peptides.

\section{Materials and Methods}

\section{Materials}

The CpG-dA with $\mathrm{dA}_{40}$ (CpG-dA), where $\mathrm{CpG}$ sequence is as follows; ATCGACTCTCGAGCGTTCTC, was synthesized by Gene Design Co., Ltd (Osaka, Japan) and purified with high-performance liquid chromatography. In this study, we used phosphorothioate (PS) backbone instead of phosphodiester (PO) backbone for dA since PS-dA forms the stable complex with SPG, compared with PO-dA [24]. SPG $\left(M_{\mathrm{w}}\right.$ $=1.5 \times 10^{5}$ as the single chain, determined with gel-permeation chromatography coupled to multi angle light scattering analysis) was kindly provided by Mitsui Sugar Co., Ltd. (Tokyo, Japan). EndoFit ${ }^{\mathrm{TM}}$ Ovalbumin (OVA) and Freund's incomplete adjuvant (IFA) were purchased from InvivoGen (San Diego, CA) and Sigma Aldrich (St. Louis, MO), respectively. Antigenic peptides, OVA peptide (SIINFEKL, amino acids 257-264 from the OVA; OVA 257-264) and mouse gp100 (EGSRNQDWL, amino acids 25-33 of mouse glycoprotein 100; gp100 $25-33$ ) were synthesized by Gene Design Co., Ltd. E.G7-OVA cells were purchased from American Type Culture Collection (Manassas, VA). The conjugate consisting of $\mathrm{OVA}_{257-264}$ and $\mathrm{dA}_{40}$ with PS backbone (OVA $257-264-\mathrm{dA}$ ) was synthesized by TAG Copenhagen A/S (Frederiksberg, Denmark).

\section{Preparation of CpG-dA/SPG (Figure 1)}

SPG was dissolved in $0.25 \mathrm{~N} \mathrm{NaOHaq}$ for 2 - 5 days to dissociate triple helix to single chain. The alkaline SPG solution, $\mathrm{CpG}-\mathrm{dA}$ in water, and phosphate buffer solution $\left(330 \mathrm{mM} \mathrm{NaH}{ }_{2} \mathrm{PO}_{4}, \mathrm{pH}=4.7\right)$ were mixed. After mixing, the mixture (CpG-dA $60 \mu \mathrm{M}, \mathrm{pH}=7.4)$ was stored at $4{ }^{\circ} \mathrm{C}$ overnight. The molar ratio ([CpG-dA]/[SPG]) was controlled to 4.0 , meaning that 8 molecules of $\mathrm{CpG}-\mathrm{dA}$ are contained in one complex. 


\section{Biodistribution of CpG-dA/SPG}

All animal experiments were performed according to the guidelines for animal care and use committee of the University of Kitakyushu. C57BL/6J mice were purchased from Japan SLC, Inc., (Shizuoka, Japan). $30 \mu \mathrm{g}$ of Alexa-647-labeled CpG-dA or CpG-dA/SPG was injected into the base of the tail. After 3 hours, the indicated tissues were homogenized with Tris-buffered saline $(20 \mathrm{mM}$ Tris, $0.1 \%$ SDS, $1 \% \mathrm{NP}-40,1 \mathrm{mM}$ EDTA, $150 \mathrm{mM} \mathrm{NaCl}$; $\mathrm{pH}$ 7.2) and centrifuged to obtain the tissue extracts. The fluorescence intensities and protein concentrations were measured with a Wallac 1420 (Perkin Elmer, Wellesley, MA) and a Protein Quantification Kit (Dojindo, Kumamoto, Japan), respectively.

\section{Immunization with $\mathrm{CpG}-\mathrm{dA} / \mathrm{SPG}$ and $\mathrm{OVA}$ or $\mathrm{OVA}_{257-264-\mathrm{dA} / \mathrm{SPG}}$}

Mice were immunized with OVA $(100 \mu \mathrm{g})$ and CpG-dA/SPG (CpG-dA; $30 \mu \mathrm{g})$ at the base of the tail twice at days 0 and 10. At day 17, blood and splenocytes were collected. For immunization with peptide antigens, mice were administered

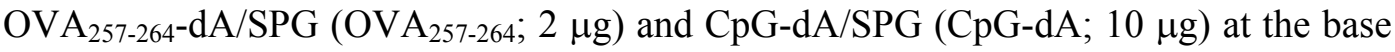
of the tail once at day 0 . At day 7 , splenocytes were collected.

Antigen specific immune responses

OVA-specific serum antibody titers were measured with enzyme linked immunosorbent assay (ELISA). Mouse splenocytes were stimulated with whole OVA protein or $\mathrm{OVA}_{257-264}$ at $10 \mu \mathrm{g} / \mathrm{ml}$ for 24 hours. The supernatants were subjected to ELISA for mouse IFN- $\gamma$. For the quantitative determination of OVA specific $\mathrm{CD}^{+}$cells, splenocytes were stimulated with $\mathrm{OVA}_{257-264}$ for 4 days and stained with $\mathrm{H}-2 \mathrm{~K}^{\mathrm{b}}$ OVA tetramer (MBL Co., Ltd., Nagoya, Japan) and mouse anti-CD8 antibody (BD Pharmingen, San Diego, CA). OVA tetramer ${ }^{+} \mathrm{CD} 8^{+}$cell numbers were determined with an EPICS $^{\circledR}$ XL (Beckman Coulter, Fullerton, CA).

\section{In vivo CTL assay}

Naïve mouse splenocytes were pulsed with or without OVA $257-264$ or gp100 $25-33$ (10 $\mu \mathrm{g} / \mathrm{ml}$ ) for $90 \mathrm{~min}$ at $37^{\circ} \mathrm{C}$. After washing three times with PBS, the peptide-pulsed and non-pulsed cells were labeled with carboxyfluorescein succinimidyl ester (CFSE; Invitrogen, Carlsbad, CA) at 5 and $0.5 \mu \mathrm{M}$, respectively, for $10 \mathrm{~min}$ at room temperature. After washing three times with PBS, equal numbers of CFSE ${ }^{\text {high }}$ (peptide-pulsed cells) and CFSE ${ }^{\text {low }}$ (non-pulsed cells) were mixed and injected intravenously into immunized mice. 24 hours later, splenocytes were collected and subjected to flow cytometry analysis.

\section{In vitro CTL assay}

C57BL/6J mice were immunized with OVA $(100 \mu \mathrm{g})$ or $\mathrm{OVA}_{257-264} \mathrm{dA} / \mathrm{SPG}$ $\left(\mathrm{OVA}_{257-264} ; 2 \mu \mathrm{g}\right)$ and $\mathrm{CpG}-\mathrm{dA} / \mathrm{SPG}(\mathrm{CpG}-\mathrm{dA} ; 30 \mu \mathrm{g})$ at the base of the tail twice at days 0 and 10. At day 17, splenocytes were collected and seeded at $1.0 \times 10^{7}$ cells in a

6-well microplate. The cells were mixed with CFSE-labeled E.G7-OVA cells $\left(1.0 \times 10^{5}\right.$ cells) and incubated at $37{ }^{\circ} \mathrm{C}$ for 24 hours. The mixture of splenocytes and 
CFSE-labeled E.G7-OVA cells $\left(\mathrm{CFSE}^{\text {high }}\right)$ was added E.G7-OVA cells with CFSE ${ }^{\text {low }}$ $\left(1.0 \times 10^{5}\right.$ cells $)$ and subjected to flow cytometry analysis.

Antitumor effects

Mice were pre-immunized with $\mathrm{OVA}_{257-264} \mathrm{dA} / \mathrm{SPG}\left(\mathrm{OVA}_{257-264} ; 2 \mu \mathrm{g}\right)$ and CpG-dA/SPG (CpG-dA; $10 \mu \mathrm{g})$ at the base of the tail on day -7 . On day 0 , mice were inoculated subcutaneously with $1.0 \times 10^{6}$ E.G7-OVA cells in the left flank. Tumor growth was monitored by measuring two axes of the tumor using digital calipers every 2-3 days. Results are presented as the mean tumor size (area in square millimeters). After tumor areas reached $230 \mathrm{~mm}^{2}$, mice were sacrificed by $\mathrm{CO}_{2}$ inhalation.

\section{Results}

\section{Biodistribution of fluorescence-labeled CpG-dA/SPG}

In order to induce high immune responses in vivo, adjuvants need to be incorporated into APCs. We previously found that CpG-dA/SPG and OVA promptly colocalize at $\mathrm{MARCO}^{+}$macrophages in the draining inguinal lymph nodes after injection at the tail base and migrate to $\mathrm{CD} 11 \mathrm{c}^{+} \mathrm{DCs}$ in the T-cell area of the inguinal lymph nodes [18]. In the present study, we examined the biodistribution of Alexa647-labelled CpG-dA/SPG in other tissues. Strong fluorescence signals of $\mathrm{CpG}-\mathrm{dA} / \mathrm{SPG}$ were observed not only in inguinal lymph nodes, but also axillary lymph nodes 3 hours after injection of tail base (Figure 2). The fluorescence intensities of $\mathrm{CpG}-\mathrm{dA} / \mathrm{SPG}$ in both lymph node groups were larger than those of $\mathrm{CpG}-\mathrm{dA}$. In particular, the fluorescence intensity of CpG-dA/SPG in axillary lymph nodes, which are farther from the administration site than inguinal lymph nodes, was three times larger than that of CpG-dA. In a previous study, when fluorescein isothiocyanate-labeled ODN-dA/SPG was injected into the mouse tail vein, the complexes were not detected in the bloodstream after $60 \mathrm{~min}$ and were largely accumulated in liver [16]. However, in the present study, CpG-dA/SPG and CpG-dA fluorescence was hardly detected in the liver, spleen, and blood circulation (data not

Figure 2

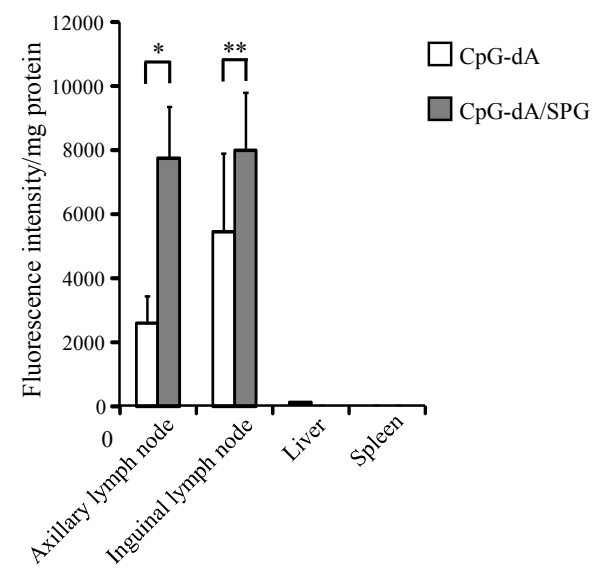


shown). $\mathrm{CpG}-\mathrm{dA} / \mathrm{SPG}$ and $\mathrm{CpG}-\mathrm{dA}$ are considered to be released slowly from the injected site and move to blood stream. However, the amounts were too small to be detected in the tissues at 3 hours after intradermal injection. This result indicates that CpG-dA and CpG-dA/SPG promptly move to lymphatic vessels and accumulate in systemic lymph nodes. CpG-dA/SPG is more likely to accumulate in lymph nodes throughout the body other than regional lymph nodes. Considering the effective induction of humoral and cellular immune responses, accumulation in immune tissues without being taken up by other tissues in blood circulation is advantageous.

\section{CpG-dA/SPG induces potent antigen specific CTL activities in vitro and in vivo}

Mice immunized with a mixture of $\mathrm{CpG}-\mathrm{dA} / \mathrm{SPG}$ and antigenic protein OVA at the tail base exhibited stronger humoral immune and T-cell responses than those immunized with a mixture of CpG-dA and OVA or IFA and OVA (Figure 3A and Supplementary Figure 1). These strong immune responses were induced only when CpG-dA was complexed with SPG, indicating complexation with SPG promotes both CD8 and CD4 $\mathrm{T}$ cell responses. We subsequently verified the CTL activities in vivo. When splenocytes from naïve mice were pulsed with OVA peptide $\mathrm{OVA}_{257-264}$ and intravenously administered to mice immunized with a mixture of $\mathrm{CpG}-\mathrm{dA} / \mathrm{SPG}$ and OVA, the $\mathrm{OVA}_{257-264}$ presenting cells were completely eliminated from recipient mice (Figure 3B). However, this CTL activity was not observed in the cells presenting another antigenic peptide gp $100_{25-33}$. Thus, the results indicate antigen-specific immune responses were induced in vivo.

Figure 3

(A)

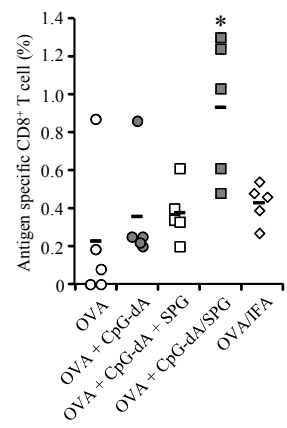

(C)
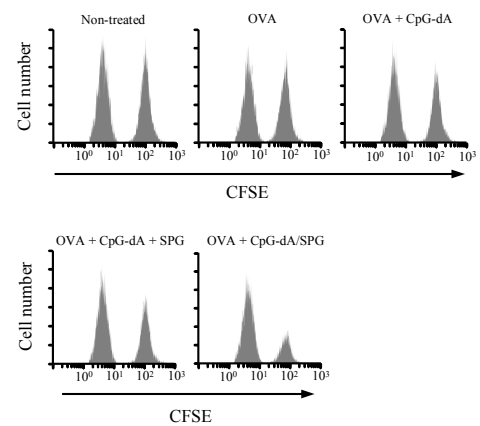

(B)

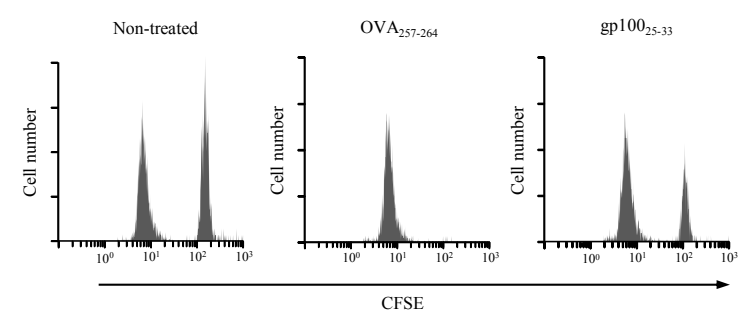

(D)

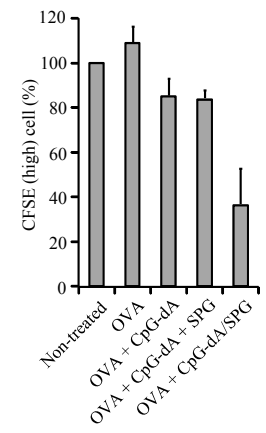


E.G7-OVA cells constitutively express OVA and are used to study $\mathrm{H}-2 \mathrm{~K}^{\mathrm{b}}$-restricted cytotoxic lymphocytes specific to OVA $257-264$ [25]. When splenocytes collected from mice immunized with a mixture of CpG-dA/SPG and OVA were added to CFSE-labeled E.G7-OVA cells (CFSE ${ }^{\text {high }}$ ), the number of CFSE ${ }^{\text {high }}$ E.G7-OVA cells decreased by $40 \%$ compared to the control CFSE ${ }^{\text {low }}$ E.G7-OVA cells (Figure 3C, D). Splenocytes from mice immunized with CpG-dA and OVA or CpG-dA, OVA, and SPG did not exhibit noticeable CTL activity for E.G7-OVA cells. These results indicate that immunization with antigenic protein and CpG-dA/SPG can induce CTL activity sufficient to kill the antigenic peptide-presenting tumor cells; this suggests the immune responses can effectively suppress tumor growth and virus infection.

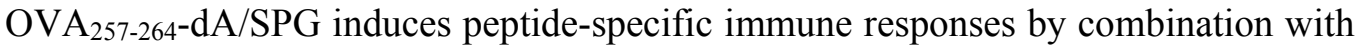
CpG-ODNs

In general, antigenic proteins are taken up by APCs and degraded by proteases and peptidases [26-28]. The resultant peptides are loaded on MHC molecules and presented on the cell surface. Thus, peptides are also suitable for antigens to induce antigen-specific immune responses. Although OVA is transported into endosomes via mannose receptor

Figure 4

(A)

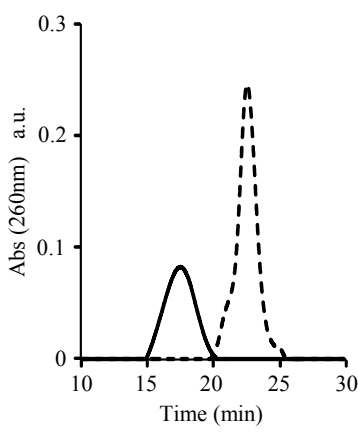

(B)

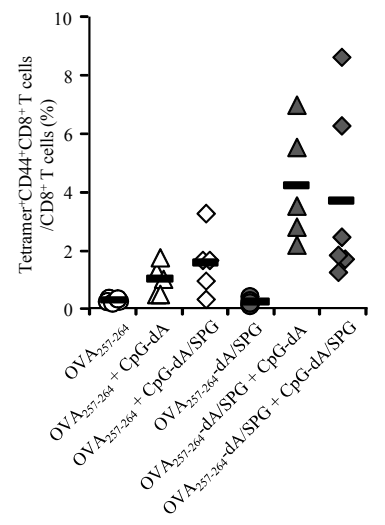

(C)

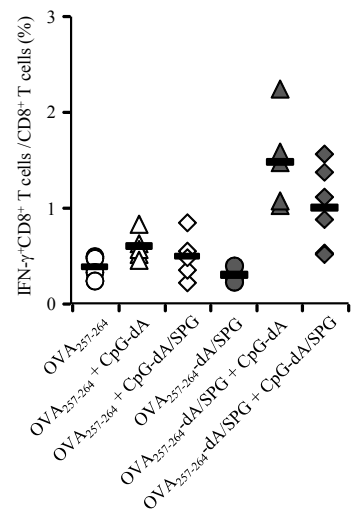

(D)
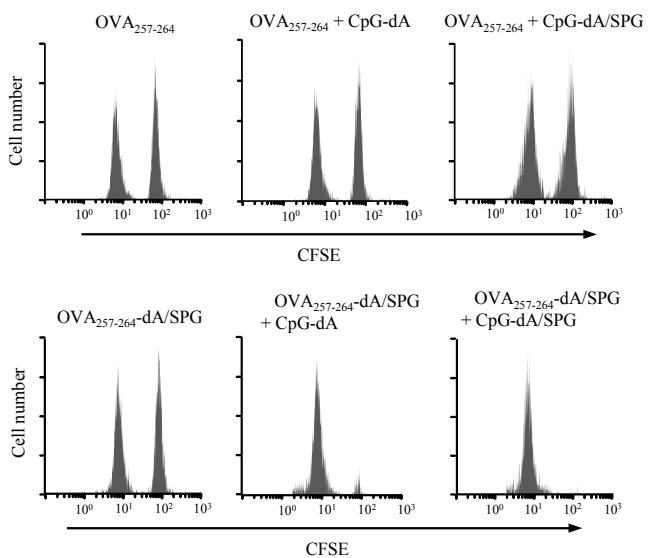

(E)

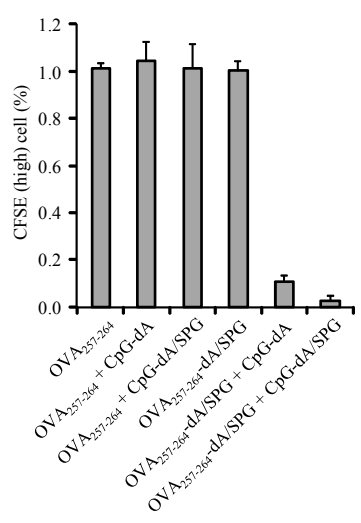


on APCs $[29,30]$, peptides are easily excreted in urine after administration into the body because of their very small molecular size [31, 32], thus necessitating a delivery carrier. To this end, we prepared peptide $\mathrm{OVA}_{257-264}$ with attached $\mathrm{dA}_{40}$ $\left(\mathrm{OVA}_{257-264}-\mathrm{dA}\right)$ and mixed it with SPG in the same manner as the preparation of CpG-dA/SPG. The GPC profiles monitored by UV absorbance at $260 \mathrm{~nm}$ showed that $\mathrm{OVA}_{257-264}$-dA has absorbance at $260 \mathrm{~nm}$ while SPG does not (Figure 4A). After the reaction, the new peak appeared at an earlier elution time, indicating increased molecular weight due to complexation. From the peak area, the complexation yield was determined to be almost $100 \%$, and we observed no degradation and aggregation.

We injected CpG-dA/SPG (we used $\mathrm{CpG}$ with phosphorothioate backbones but not phosphodiester linkages) and the obtained complex (i.e., OVA257-264-dA/SPG; Figure 1) at the tail base of mice and evaluated immune response induction. The most important immune response for effective immunotherapy is the increment of IFN- $\gamma^{+} \mathrm{T}$-cell

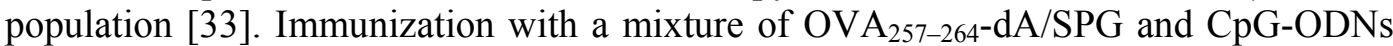
increased $\mathrm{OVA}_{257-264}$-specific $\mathrm{CD}^{+} \mathrm{T}$ cells and $\mathrm{T}$-cell populations that secrete IFN- $\gamma$ (Figure 4B, C). Meanwhile, immunization with $\mathrm{OVA}_{257-264}$ did not induce CTL activities regardless of co-administration with CpG-ODNs. These results indicate that peptides require delivery vehicles to induce specific CTL activities when used as antigens. However, unlike protein antigens, there was no significant difference between immunization with $\mathrm{CpG}-\mathrm{dA}$ and $\mathrm{CpG}-\mathrm{dA} / \mathrm{SPG}$ when simultaneously administered with

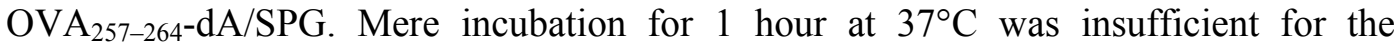
progression of the complexation between $\mathrm{CpG}-\mathrm{dA}$ and $\mathrm{OVA}_{257-264-\mathrm{dA} / \mathrm{SPG}}$ (Supplementary Figure 2), indicating that sufficient uptake of $\mathrm{OVA}_{257-264}$ into APCs enables the induction of immune responses given that at least some CpG-ODNs are delivered into APCs.

Figure 4D shows the histograms of CFSE-labeled splenocytes injected into and collected from mice immunized with the indicated antigens and adjuvants. OVA peptide-pulsed splenocytes $\left(\mathrm{CFSE}^{\text {high }}\right)$ were almost eliminated from the mice immunized with a mixture of $\mathrm{OVA}_{257-264} \mathrm{dA} / \mathrm{SPG}$ and $\mathrm{CpG}$ or $\mathrm{CpG}-\mathrm{dA} / \mathrm{SPG}$. As expected, there were no significant differences between the numbers of CFSE ${ }^{\text {high }}$ and $\mathrm{CFSE}^{\text {low }}$ (non-pulsed) splenocytes from mice immunized with $\mathrm{OVA}_{257-264}$, $\mathrm{OVA}_{257-}$ 264-dA/SPG, OVA $257-264$ and CpG-dA, or OVA $257-264$ and CpG-dA/SPG (Figure 4D, E). The numbers of splenocytes pulsed with another antigen, gp100 ${ }_{25-33}$, and non-pulsed splenocytes were almost the same (Supplementary Figure 3), indicating that this CTL activity is responsive to cells with immunized antigenic peptides specifically in vivo.

In summary, the prepared $\mathrm{OVA}_{257-264} \mathrm{dA} / \mathrm{SPG}$ can induce $\mathrm{OVA}_{257-264}$ specific immune responses in combination with $\mathrm{CpG}$ or $\mathrm{CpG}-\mathrm{dA} / \mathrm{SPG}$ both in vitro and in vivo, indicating that antigenic peptides are essential to be complexed with SPG for induction of antigen-specific CTL activities.

Suppression of $\mathrm{OVA}_{257-264}$-bearing tumor growth by immunization with

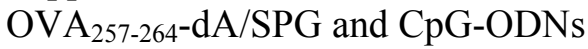

When splenocytes collected from the mice immunized with a mixture of

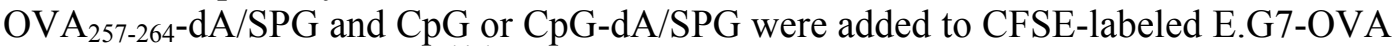
cells, the number of CFSE ${ }^{\text {high }}$ E.G7-OVA cells decreased by $80 \%$ compared to the control CFSE ${ }^{\text {low }}$ 
Figure 5

(A)
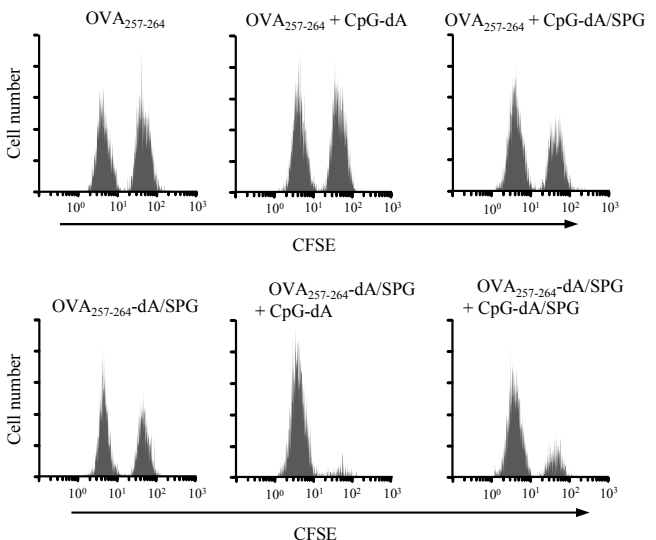

(B)

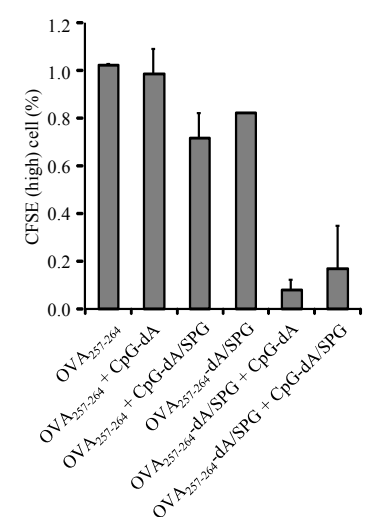

(C)
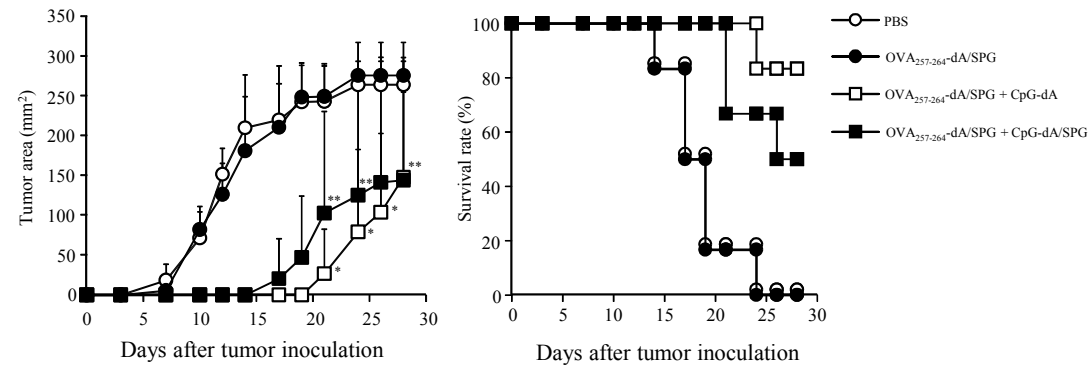

E.G7-OVA cells (Figure 5A, B). This result indicates that CFSE ${ }^{\text {high }}$ E.G7-OVA cells were killed by immunization-induced CTLs. The numbers of E.G7-OVA cells treated with splenocytes from mice immunized with $\mathrm{OVA}_{257-264}$ or a mixture of $\mathrm{OVA}_{257-264}$ and CpG-dA were almost the same as that of control CFSE ${ }^{\text {low }}$ E.G7-OVA cells; this indicates that the immunization did not induce any CTL activities. The CTL activities induced by immunization with $\mathrm{OVA}_{257-264}-\mathrm{dA} / \mathrm{SPG}$ or a mixture of $\mathrm{OVA}_{257-264}$ and CpG-dA/SPG decreased the number of E.G7-OVA cells by $20 \%$, which was much weaker than that induced by immunization with a mixture of $\mathrm{OVA}_{257-264} \mathrm{dA} / \mathrm{SPG}$ and CpG-dA/SPG.

We evaluated the preventive effect of immunization with $\mathrm{OVA}_{257-264} \mathrm{dA} / \mathrm{SPG}$ and $\mathrm{CpG}-\mathrm{dA} / \mathrm{SPG}$ on tumor growth. As shown in Figure 5C, mice immunized with $\mathrm{OVA}_{257-}$ 264-dA/SPG and CpG-dA or $\mathrm{OVA}_{257-264}-\mathrm{dA} / \mathrm{SPG}$ and $\mathrm{CpG}-\mathrm{dA} / \mathrm{SPG}$ exhibited long delays in tumor growth compared with those treated with phosphate-buffered saline (PBS), OVA $257-264$ alone, or OVA $257-264-\mathrm{dA} / \mathrm{SPG}$ alone. In particular, tumor growth did

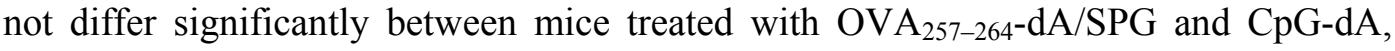

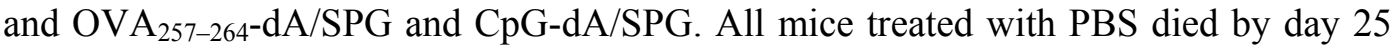

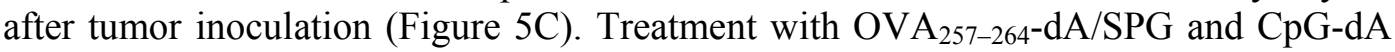
or $\mathrm{OVA}_{257-264}-\mathrm{dA} / \mathrm{SPG}$ and $\mathrm{CpG}-\mathrm{dA} / \mathrm{SPG}$ yielded over $60 \%$ survival at day 25 , whereas other treatments showed no improvement. These results indicate that not only antigenic proteins, but also peptides complexed with SPG can induce strong CTL activity in combination with moderate amounts of CpG-ODNs; this kills the antigenic peptide-presenting tumor cells and effectively suppresses tumor growth in a prophylaxis cancer vaccine model. 


\section{Discussion}

Various novel cancer therapies using molecular-targeted drugs and antibody-drug conjugates have been developed with the aim of replacing chemotherapy and radiation therapy [34]. Moreover, cancer vaccine therapy is one of the most promising types of candidate therapies. However, the administration of free antigenic proteins or peptides will likely induce little CTL activity; this is because these antigens are taken up by nonspecific cells and not APCs, leading to CTL anergy through the absence of appropriate immune stimulation [35]. Therefore, the induction of effective CTL activity via vaccination requires substantial advancements. The present study demonstrates immunization with a mixture of $\mathrm{CpG}-\mathrm{dA} / \mathrm{SPG}$ and OVA or $\mathrm{OVA}_{257-264} \mathrm{dA} / \mathrm{SPG}$ can induce antigen-specific immune responses and kill tumor model cells.

CpG-dA/SPG is likely to accumulate in lymph nodes (Figure 2) and be taken up by $\mathrm{MARCO}^{+}$macrophages [18]; because we did not observe high uptake into cells with administration of $\mathrm{CpG}-\mathrm{dA}$ alone, this uptake is attributed to the recognition of SPG or $\mathrm{dA} / \mathrm{SPG}$ by some kind of $\beta$-glucan receptor. We demonstrated that $\mathrm{dA} / \mathrm{SPG}$ and SPG alone can bind to the representative $\beta$-glucan receptor Dectin-1 [36]. However, Dectin-1 is not closely involved in the adjuvant activities of CpG-dA/SPG [18]. In the present study, we did not observe the difference in the immune responses between naïve and Dectin-1 knockout mice immunized with $\mathrm{OVA}_{257-264}-\mathrm{dA} / \mathrm{SPG}$ and CpG-dA/SPG (data not shown), indicating that Dectin-1 is not involved in the uptake of

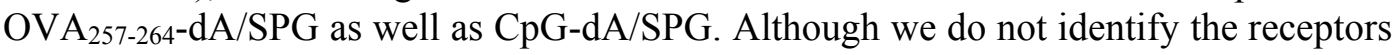
involved in this uptake, these results suggest that $\mathrm{dA} / \mathrm{SPG}$ can bind to other $\beta$-glucan receptors and $\mathrm{OVA}_{257-264}-\mathrm{dA} / \mathrm{SPG}$ also exhibits the same biodistribution as $\mathrm{CpG}-\mathrm{dA} / \mathrm{SPG}$. Considering the rapid clearance of peptides in biological fluids, the specific delivery of antigenic peptides to APCs by using SPG enables the induction of sufficient antigen-specific CTL responses. In fact, immunization with $\mathrm{OVA}_{257-264}$ alone or in combination with $\mathrm{CpG}-\mathrm{dA} / \mathrm{SPG}$ did not induce CTL activity. Meanwhile, strong immune responses and CTL activities were induced when $\mathrm{OVA}_{257-264-\mathrm{dA} / \mathrm{SPG} \text { was }}$ used as an antigen. However, these activities were observed in combination with not only CpG-dA/SPG, but CpG-dA as well (Figures 4, 5). These results indicate that CpG delivery using SPG is not essential for inducing antigen-specific CTL activities as long as peptides are delivered to APCs. Antigen-specific immune responses can be triggered by uptake of a sufficient amount of antigen and adjuvant into APCs. In the present study, administration of $\mathrm{OVA}_{257-264}$ at $2 \mu \mathrm{g} /$ mouse was sufficient to induce immune responses even with only a small amount of CpG-ODN uptake. On the other hand, as the amounts of OVA proteins incorporated into APCs were inadequate to induce immune responses in combination with $\mathrm{CpG}-\mathrm{dA}$, further uptake of $\mathrm{CpG}-\mathrm{dA}$ by complexation with SPG is required. These findings indicate that antigen-specific CTL activities can be induced with a lower dose of $\mathrm{OVA}_{257-264} / \mathrm{SPG}$ than that used in the present study. In fact, we demonstrated the various therapeutic effects with the significant low dose of therapeutic ODNs by using SPG [15-17]. Nevertheless, the optimization of the ratios of doses

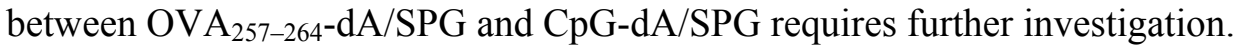

When foreign proteins are incorporated into APCs, they promptly follow one of two intracellular pathways for antigen presentation [26, 27]. First, antigenic proteins are translocated from endosomes to the cytosol where they are degraded by proteasomes, resulting in peptide fragments 2-25 residues long [37], which are subsequently 
transported into the endoplasmic reticulum for loading onto MHC class I molecules. In the second pathway, the degraded peptides within endosomal compartments are loaded on MHC class I molecules recycled from the plasma membrane and transported back to the cell surface. In the present study, we used 8-amino-acid peptides conjugated with $\mathrm{dA}_{40}(\mathrm{~S})$ by click chemistry between the C-terminal amino acid and 5'-terminal nucleic acid. As linkages containing a triazole ring are not considered to cleave in endosomal compartments or cytosol by enzymes, the resultant peptides loaded onto MHC class I molecules can be less than 8 amino acids. Peptides of 8-10 residues are suitable for stable assembly with MHC class I molecules in the endoplasmic reticulum [38]. Even though the trimmed peptides are too short to load on MHC class I molecules, OVA $257-$ 264-dA/SPG can induce the peptide-specific CTL activities. This corroborates the specific delivery into APCs by complexation with SPG as well as CpG-ODNs. The optimal $\mathrm{N}$ - and $\mathrm{C}$-terminal sequences for trimming by peptidase and loading onto $\mathrm{MHC}$ class I molecules are known [39]. Therefore, optimizing the peptide design for trimming by peptidase would achieve similar CTL activities at a lower dose than that used in the present study. We previously demonstrated that antisense ODNs complexed with SPG bind target mRNAs without dissociation from the complex [15]. As another route for presentation, these findings suggest $\mathrm{OVA}_{257-264} \mathrm{dA} / \mathrm{SPG}$ can be loaded on MHC class I molecules without trimming by peptidase within endosomal compartments. Although the intracellular movement of $\mathrm{OVA}_{257-264}-\mathrm{dA} / \mathrm{SPG}$ is unknown, its elucidation could aid the optimization of peptide design and enhance effects of CTL activities.

In conclusion, immunization with a mixture of OVA and CpG-dA/SPG induced antigen-specific CTL activities, killing the antigenic peptide-presenting tumor cells. When peptides are used as antigens, immunization with a mixture of $\mathrm{OVA}_{257-264}$ and CpG-DNA/SPG did not induce any CTL activity. Immunization with OVA $257-264$ complexed with SPG induced strong CTL activity both in vitro and in vivo in combination with $\mathrm{CpG}-\mathrm{dA}$ (or CpG-dA/SPG). These results can be attributed to the cell-specific delivery because of the use of SPG. Therefore, peptide-dA/SPG and $\mathrm{CpG}-\mathrm{dA} / \mathrm{SPG}$ complexes have great potential as vaccines for the treatment of cancers and infectious diseases.

\section{Acknowledgements}

We would like to gratefully thank Ms. Motoko Tanaka for her help. This work was financially supported by a JST NexTEP program.

\section{References}

[1] I. Mellman, G. Coukos, G. Dranoff, Cancer immunotherapy comes of age, Nature, 480 (2011) 480-489.

[2] M. Dougan, G. Dranoff, Immune therapy for cancer, Annu. Rev. Immunol., 27 (2009) 83-117.

[3] X. Hu, N.G. Chakraborty, J.R. Sporn, S.H. Kurtzman, M.T. Ergin, B. Mukherji, Enhancement of cytolytic $\mathrm{T}$ lymphocyte precursor frequency in melanoma patients following immunization with the MAGE-1 peptide loaded antigen presenting cell-based vaccine, Cancer Res., 56 (1996) 2479-2483. 
[4] P. van der Bruggen, C. Traversari, P. Chomez, C. Lurquin, E. De Plaen, B. Van den Eynde, A. Knuth, T. Boon, A gene encoding an antigen recognized by cytolytic T lymphocytes on a human melanoma, Science, 254 (1991) 1643-1647.

[5] J.M. Blander, R. Medzhitov, Toll-dependent selection of microbial antigens for presentation by dendritic cells, Nature, 440 (2006) 808-812.

[6] D.W. O'Neill, S. Adams, N. Bhardwaj, Manipulating dendritic cell biology for the active immunotherapy of cancer, Blood, 104 (2004) 2235-2246.

[7] J. Banchereau, A.K. Palucka, Dendritic cells as therapeutic vaccines against cancer, Nat. Rev. Immunol., 5 (2005) 296-306.

[8] E. Gilboa, DC-based cancer vaccines, J. Clin. Invest., 117 (2007) 1195-1203.

[9] H. Hemmi, O. Takeuchi, T. Kawai, T. Kaisho, S. Sato, H. Sanjo, M. Matsumoto, K. Hoshino, H. Wagner, K. Takeda, S. Akira, A Toll-like receptor recognizes bacterial DNA, Nature, 408 (2000) 740-745.

[10] A.M. Krieg, Therapeutic potential of Toll-like receptor 9 activation, Nat. Rev. Drug Discov., 5 (2006) 471-484.

[11] R.S. Chu, O.S. Targoni, A.M. Krieg, P.V. Lehmann, C.V. Harding, CpG oligodeoxynucleotides act as adjuvants that switch on T helper 1 (Th1) immunity, J. Exp. Med., 186 (1997) 1623-1631.

[12] C.L. Brazolot Millan, R. Weeratna, A.M. Krieg, C.A. Siegrist, H.L. Davis, CpG DNA can induce strong Th1 humoral and cell-mediated immune responses against hepatitis B surface antigen in young mice, Proc. Natl. Acad. Sci. U. S. A., 95 (1998) 15553-15558.

[13] K. Sakurai, S. Shinkai, Molecular Recognition of Adenine, Cytosine, and Uracil in a Single-Stranded RNA by a Natural Polysaccharide: Schizophyllan, J. Am. Chem. Soc., 122 (2000) 4520-4521.

[14] K. Sakurai, M. Mizu, S. Shinkai, Polysaccharide--polynucleotide complexes. 2. Complementary polynucleotide mimic behavior of the natural polysaccharide schizophyllan in the macromolecular complex with single-stranded RNA and DNA, Biomacromolecules, 2 (2001) 641-650.

[15] S. Mochizuki, K. Sakurai, Dectin-1 targeting delivery of TNF-alpha antisense ODNs complexed with beta-1,3-glucan protects mice from LPS-induced hepatitis, J. Control. Release, 151 (2011) 155-161.

[16] S. Mochizuki, H. Morishita, K. Sakurai, Macrophage specific delivery of TNF-alpha siRNA complexed with beta-1,3-glucan inhibits LPS-induced cytokine production in a murine acute hepatitis model, Bioorg. Med. Chem., 21 (2013) 2535-2542.

[17] H. Takedatsu, K. Mitsuyama, S. Mochizuki, T. Kobayashi, K. Sakurai, H. Takeda, Y. Fujiyama, Y. Koyama, J. Nishihira, M. Sata, A new therapeutic approach using a schizophyllan-based drug delivery system for inflammatory bowel disease, Mol. Ther., 20 (2012) 1234-1241.

[18] K. Kobiyama, T. Aoshi, H. Narita, E. Kuroda, M. Hayashi, K. Tetsutani, S. Koyama, S. Mochizuki, K. Sakurai, Y. Katakai, Y. Yasutomi, S. Saijo, Y. Iwakura, S. Akira, C. Coban, K.J. Ishii, Nonagonistic Dectin-1 ligand transforms CpG into a multitask nanoparticulate TLR9 agonist, Proc. Natl. Acad. Sci. U. S. A., 111 (2014) 3086-3091.

[19] H.S. Goodridge, A.J. Wolf, D.M. Underhill, Beta-glucan recognition by the innate immune system, Immunol. Rev., 230 (2009) 38-50. 
[20] L. Bungener, K. Serre, L. Bijl, L. Leserman, J. Wilschut, T. Daemen, P. Machy, Virosome-mediated delivery of protein antigens to dendritic cells, Vaccine, 20 (2002) 2287-2295.

[21] Q. Wang, M.T. Tan, B.P. Keegan, M.A. Barry, M.J. Heffernan, Time course study of the antigen-specific immune response to a PLGA microparticle vaccine formulation, Biomaterials, 35 (2014) 8385-8393.

[22] Y. Yoshizaki, E. Yuba, N. Sakaguchi, K. Koiwai, A. Harada, K. Kono, Potentiation of $\mathrm{pH}$-sensitive polymer-modified liposomes with cationic lipid inclusion as antigen delivery carriers for cancer immunotherapy, Biomaterials, 35 (2014) 8186-8196.

[23] E.S. Trombetta, I. Mellman, Cell biology of antigen processing in vitro and in vivo, Annu. Rev. Immunol., 23 (2005) 975-1028.

[24] S. Mochizuki, K. Sakurai, beta-1,3-Glucan/antisense oligonucleotide complex stabilized with phosphorothioation and its gene suppression, Bioorg. Chem., 38 (2010) 260-264.

[25] M.W. Moore, F.R. Carbone, M.J. Bevan, Introduction of soluble protein into the class I pathway of antigen processing and presentation, Cell, 54 (1988) 777-785.

[26] E. Segura, J.A. Villadangos, A modular and combinatorial view of the antigen cross-presentation pathway in dendritic cells, Traffic, 12 (2011) 1677-1685.

[27] L. Cohn, L. Delamarre, Dendritic cell-targeted vaccines, Front. Immunol., 5 (2014) 255.

[28] E.J. Sijts, P.M. Kloetzel, The role of the proteasome in the generation of MHC class I ligands and immune responses, Cell. Mol. Life Sci., 68 (2011) 1491-1502.

[29] S. Burgdorf, V. Schuette, V. Semmling, K. Hochheiser, V. Lukacs-Kornek, P.A. Knolle, C. Kurts, Steady-state cross-presentation of OVA is mannose receptor-dependent but inhibitable by collagen fragments, Proc. Natl. Acad. Sci. U. S. A., 107 (2010) E48-49; author reply E50-41.

[30] E. Segura, A.L. Albiston, I.P. Wicks, S.Y. Chai, J.A. Villadangos, Different cross-presentation pathways in steady-state and inflammatory dendritic cells, Proc. Natl. Acad. Sci. U. S. A., 106 (2009) 20377-20381.

[31] D.E. Milenic, T. Yokota, D.R. Filpula, M.A. Finkelman, S.W. Dodd, J.F. Wood, M. Whitlow, P. Snoy, J. Schlom, Construction, binding properties, metabolism, and tumor targeting of a single-chain $\mathrm{Fv}$ derived from the pancarcinoma monoclonal antibody CC49, Cancer Res., 51 (1991) 6363-6371.

[32] S.M. Larson, J.A. Carrasquillo, K.A. Krohn, J.P. Brown, R.W. McGuffin, J.M. Ferens, M.M. Graham, L.D. Hill, P.L. Beaumier, K.E. Hellstrom, et al., Localization of 131I-labeled p97-specific Fab fragments in human melanoma as a basis for radiotherapy, J. Clin. Invest., 72 (1983) 2101-2114.

[33] C. Becker, H. Pohla, B. Frankenberger, T. Schuler, M. Assenmacher, D.J. Schendel, T. Blankenstein, Adoptive tumor therapy with $\mathrm{T}$ lymphocytes enriched through an IFN-gamma capture assay, Nat. Med., 7 (2001) 1159-1162.

[34] D.M. Pardoll, The blockade of immune checkpoints in cancer immunotherapy, Nat. Rev. Cancer, 12 (2012) 252-264.

[35] R.M. Steinman, D. Hawiger, M.C. Nussenzweig, Tolerogenic dendritic cells, Annu. Rev. Immunol., 21 (2003) 685-711.

[36] S. Mochizuki, H. Morishita, Y. Adachi, Y. Yamaguchi, K. Sakurai, Binding assay between murine Dectin-1 and beta-glucan/DNA complex with quartz-crystal microbalance, Carbohydr. Res., 391 (2014) 1-8. 
[37] A.F. Kisselev, T.N. Akopian, K.M. Woo, A.L. Goldberg, The sizes of peptides generated from protein by mammalian 26 and $20 \mathrm{~S}$ proteasomes. Implications for understanding the degradative mechanism and antigen presentation, J. Biol. Chem., 274 (1999) 3363-3371.

[38] D.R. Madden, The three-dimensional structure of peptide-MHC complexes, Annu. Rev. Immunol., 13 (1995) 587-622.

[39] S.C. Chang, F. Momburg, N. Bhutani, A.L. Goldberg, The ER aminopeptidase, ERAP1, trims precursors to lengths of MHC class I peptides by a "molecular ruler" mechanism, Proc. Natl. Acad. Sci. U. S. A., 102 (2005) 17107-17112.

\section{Figure captions}

Figure 1.

A schematic illustration to show a complex structure made from CpG-ODN or $\mathrm{OVA}_{257-264}$ with $\mathrm{dA}_{40}$ tail and SPG. A triple-stranded complex is formed from one DNA and two SPG strands with the interactions between two SPG main-chain glucoses (mG) and one $\mathrm{dA}$.

Figure 2.

Biodistribution of Alexa647-labelled CpG-dA/SPG. The fluorescence intensity in axillary and inguinal lymph nodes, liver and spleen was measured at 3 hours after injection. Results represent the mean \pm S.D. $(\mathrm{n}=3)$. ${ }^{*} P<0.01,{ }^{* *} P<0.05$.

Figure 3.

Induction of potent CTL activities by immunization with CpG-dA/SPG and OVA in vitro and in vivo. (A) OVA-specific $\mathrm{CD} 8^{+} \mathrm{T}$ cells were measured after immunization with OVA and indicated adjuvants $(n=6) * P<0.05$. (B) In vivo CTL activity for cells pulsed with $\mathrm{OVA}_{257-264}$ or gp100 $25-33$ after immunization with CpG-dA/SPG and OVA. (C and D) In vitro CTL activity after immunization with OVA and indicated adjuvant. Results represent the mean \pm S.D. $(n=3)$.

Figure 4.

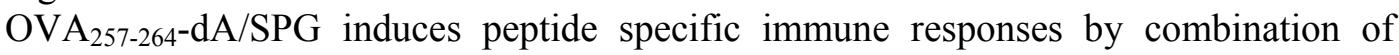
CpG-ODNs. (A) GPC chromatograms of CpG-dA (dashed line) and reaction mixture with SPG (solid line). The eluant was measured with UV absorbance at $260 \mathrm{~nm}$. (B and C) $\mathrm{OVA}_{257-264}$ peptide specific or $\mathrm{IFN}^{-} \gamma^{+} \mathrm{CD}^{+} \mathrm{T}$ cells were measured after immunization with indicated antigens and adjuvants $(n=6)$. (D and E) In vivo CTL activity for cells pulsed with $\mathrm{OVA}_{257-264}$ peptide after immunization with indicated antigens and adjuvants.

Results represent the mean \pm S.D. $(n=2)$.

Figure 5.

Immunization with $\mathrm{OVA}_{257-264} \mathrm{dA} / \mathrm{SPG}$ and $\mathrm{CpG}-\mathrm{ODNs}$ suppresses the tumor growth bearing $\mathrm{OVA}_{257-264}$ on cell surface. (A and B) In vitro CTL activity after immunization with indicated antigens and adjuvants. Results represent the mean \pm S.D. $(n=3)$. (C) Changes of tumor areas (left) and mortality (right) were monitored after tumor 
inoculation $(n=6) .{ }^{*} P<0.01,{ }^{*} P P<0.05$ versus the mice immunized with

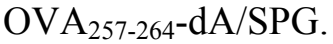


Graphical Abstract

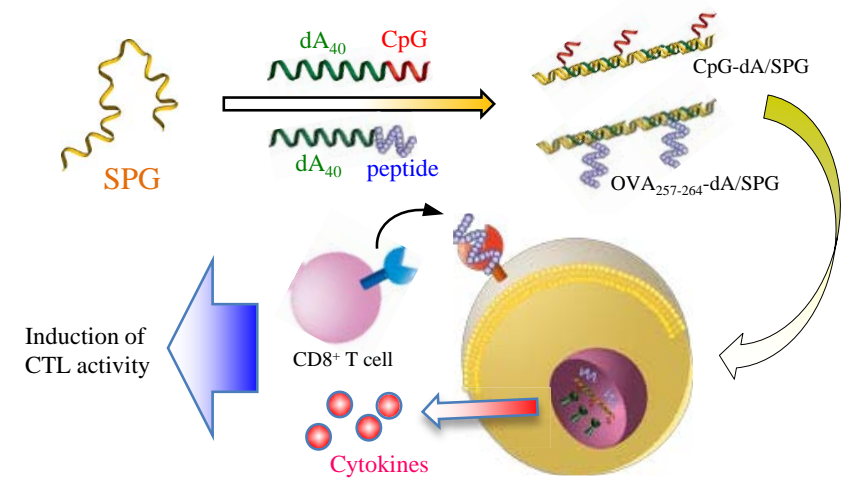

Immunization with a mixture of peptide-dA/SPG and CpG-dA/SPG complexes induced strong CTL activity, killing the antigenic peptide-presenting tumor cells. 